\title{
Calotropis procera (Ait.) Apocynaceae cultivada em substratos orgânicos
}

\section{Calotropis procera (Ait.) Apocynaceae grown on organic substrates}

\author{
Francisco José Carvalho Moreira ${ }^{1}$, Ademir Silva Menezes ${ }^{* 2}$, Francisco Mikael Oliveira Nascimento ${ }^{3}$, Maria Elisâgela Souza \\ Silva ${ }^{4}$, Luis Gonzaga Pinheiro Neto ${ }^{5}$
}

Resumo: Várias são as fontes de insumos orgânicos que podem ser utilizadas no meio agrícola para a produção de mudas. Objetivou-se com este trabalho avaliar a porcentagem de emergência de plântulas de ciúme (Calotropis procera) e seu crescimento inicial em diferentes substratos, no sentido de averiguar qual dos substratos apresenta melhor comportamento para esta espécie. O experimento foi conduzido no Instituto Federal do Ceará Campus Sobral, sendo doze substratos areia; Solo; Esterco caprino; Bagana; fibra de coco; Areia + esterco; Areia + fibra de coco; Areia + bagana; Solo + esterco caprino; Solo + fibra de coco; Solo + bagana; Solo + esterco caprino + bagana) com quatro repetições. Foi mensurada a porcentagem de emergência, altura das plantas, diâmetro caulinar e número de folha, comprimento de raiz, massa seca da parte aérea e massa seca de raiz das plantas de ciúme. Os substratos quando combinados com fibra de coco, bagana e esterco caprino proporcionam melhores condições de vigor e melhor desenvolvimento da parte aérea das plantas de ciúme. Os substratos considerados não ideais para emergência de plântulas de C. procera são esterco caprino e solo + esterco caprino.

Palavras-chave: Plantas espontâneas; Germinação; Matéria orgânica; Bagana de carnaúba.

\begin{abstract}
There are several sources of organic inputs that can be used in the agricultural environment for the production of seedlings. The objective of this work was to evaluate the percentage of emergence of jealous seedlings (Calotropis procera) and their initial growth in different substrates, in order to determine which of the substrates presents the best behavior for this species. The experiment was conducted at the Federal Institute of Ceará Campus Sobral, with twelve sand substrates; Ground; Goat manure; Bagana; coconut fiber; Sand + manure; Sand + coconut fiber; Sand + bagana; Soil + goat manure; Solo + coconut fiber; Solo + bagana; Soil + goat manure + bagana) with four replicates. The percentage of emergence, plant height, stem diameter and leaf number, root length, dry shoot mass and root dry mass of jealous plants were measured. The substrates when combined with coconut fiber, bagana and goat manure provide better conditions of vigor and better development of the aerial part of the plants of jealousy. The substrates considered not ideal for emergence of $C$. procera seedlings are manure goat and soil + goat manure.
\end{abstract}

Key words: Spontaneous plants; Germination; Organic matter; Carnauba straw.

\footnotetext{
*Autor para correspondência

Recebido para publicação em 08/02/2018; aprovado em 11/03/2018

${ }^{1}$ Doutorando em Biotecnologia, Universidade Federal do Rio Grande do Norte, Natal; (88) 3112-8100, franzecm@ gmail.com.

${ }^{2}$ Mestre em Ciência do Solo, Empresa de Assistência Técnica e Extensão Rural do Ceará, ademir.menezes@ematerce.ce.gov.br

${ }^{3}$ Tecnólogo em Irrigação e Drenagem , Instituto Federal de Educação, Ciência e Tecnologia do Ceará, mikaelnascimento5@gmail.com

${ }^{4}$ Tecnóloga em Irrigação e Drenagem , Instituto Federal de Educação, Ciência e Tecnologia do Ceará, elisangelamoraujo@gmail.com

${ }^{5}$ Doutor em Fitotecnia, Instituto Federal de Educação, Ciência e Tecnologia do Ceará, luis.neto@ifce.edu.br
} 


\section{INTRODUÇÃO}

A espécie Calotropis procera, (Ait.) R. Br. (Apocynaceae) é originária da África, Índia e Pérsia, de ocorrência comum na região Nordeste do Brasil, conhecida popularmente como "ciúme", "ciumeira" ou "algodão de seda", "flor de seda" (JOLY, 1979; MELLO et al., 2001; BARROS et al., 2004). A $C$. procera possui uma ampla distribuição geográfica, com ocorrências em regiões tropicais e subtropicais de todo o globo. A introdução desta planta no Brasil passou a se comportar como invasora de áreas de pastagens (FABRICANTE et al., 2013), problema comum em várias regiões do Nordeste brasileiro, em decorrência da maior população desta espécie no bioma Caatinga, no entanto, esta espécie pode ser usada tanto como suporte forrageiro quanto medicinal.

O "ciúme" é uma espécie de fácil adaptação, principalmente em regiões com precipitação anual variando de 150 a $1000 \mathrm{~mm}$, é uma planta que pode ser encontrada em solos excessivamente drenados, arenosos e degradados, além disso, é uma planta resistente à seca, ou seja, pode se desenvolver em ambientes com baixo conteúdo de água no solo, deste modo, contribui para a manutenção de alimentos para animais no período de estiagem na região Nordeste, fato que justifica a facilidade de encontrar tal espécie na Caatinga em grande população. Segundo Lindley (1985) ela pode ser encontrada em regiões com mais de $1000 \mathrm{~m}$ de altitude na Índia.

Para a produção de mudas bem vigorosas, necessita-se de características específicas e controladas (GOMES et al., 2002), bem como as formas de proteção inicial e manejo adequado, no sentido de uniformizar o crescimento das plantas tornando-as mais resistentes a intempéries.

A C. procera também apresenta forte potencial forrageiro, sendo utilizada na produção de feno devido à permanência de suas folhas, mesmo durante os períodos mais críticos de escassez hídrica na região semiárida, além disso, possui elevado teor de proteína bruta e pode ser cultivada em solos salinos (TORRES et al., 2010). Há informação na literatura afirmando ser a $C$. procera rica em proteína bruta e de elevada digestibilidade da matéria seca, importante para a alimentação de caprinos na forma ensilada ou fenada (MELLO et al., 2001; OLIVEIRA; SOUTO, 2009; GARCEZ et al., 2014).

Na medicina tradicional, diversas partes desta planta são utilizadas no tratamento de úlceras, tumores e doenças hepáticas (TANIRA, 1994). Vários estudos realizados com as folhas da $C$. procera, mostraram diversas atividades biológicas, como do tipo hipotensora; analgésica e antiinflamatória; atividade antibacteriana contra as cepas de Klebsiella pneumoniae, Shigella flexneri, Hafnia alvei e Staphylococus aureus; atividade anticolinérgica muscarínica (GALLEGOS-OLEA et al., 2008). Segundo Silva et al. (2015) diferentes partes dessa planta possuem várias propriedades farmacológicas, tais como caule, frutas, raízes, folhas e o látex. Neste sentido, é importante se pensar em cultivo de mudas desta espécie com finalidade medicinal, de modo que não atrapalhe as espécies forrageiras e outras da Caatinga.

Quanto à propagação desta espécie no Nordeste brasileiro, a mesma ocorre na forma vegetativa ou por semente, é facilmente disseminada pelo vento, no entanto, ainda é pouco discutida, assim, confirmando a carência de informações sobre tal planta.

$\mathrm{O}$ desenvolvimento de qualquer planta depende, entre outros fatores, do substrato adequado, pois, este exerce importante influência sobre a emergência de plântulas e qualidade das mudas (ALEXANDRE et al., 2006; WAGNER JUNIOR et al., 2006). De acordo com Brasil (2009), o tipo de substrato usado deve ser adequado às exigências fisiológicas da germinação, tamanho e forma da semente, além disso, deverá apresentar características químicas e físicas adequadas para o desempenho da muda. Para que a disponibilidade de água durante a germinação e o desenvolvimento das plantas seja adequada, o tipo de substrato utilizado é fundamental, principalmente em função de fatores como estrutura, aeração e capacidade de retenção de água (DIAS et al., 2008; MENEZES et al., 2013).

Neste sentido, objetivou-se avaliar a porcentagem de emergência de plântulas de $C$. procera e seu crescimento inicial em diferentes substratos, no sentido de averiguar qual dos substratos esta espécie apresenta-se melhor comportamento, além disso, incrementar a informação para o cultivo alternativo desta espécie como medicinal e forrageira no Nordeste brasileiro.

\section{MATERIAL E MÉTODOS}

$\mathrm{O}$ experimento foi conduzido em ambiente telado no Instituto Federal do Ceará, IFCE/Campus Sobral, no período de janeiro a fevereiro de 2017, localizado nas coordenadas geográficas S $03^{\circ} 41^{\prime} 10^{\prime}$ " e W 40²0'59" com altitude de $70 \mathrm{~m}$. O clima está classificado de acordo com Köppen como Aw', tropical quente chuvoso semiárido com pluviometria média anual de $854 \mathrm{~mm}$, temperatura média de $36{ }^{\circ} \mathrm{C}$ (BRASIL, 1990).

As sementes utilizadas neste ensaio foram coletadas no município de Sobral, Estado do Ceará, em janeiro de 2017. Após a coleta, foram encaminhados para o Laboratório de Fitossanidade e Sementes, do IFCE/Campus Sobral, onde foram selecionadas e colocadas em potes de polietileno para armazenamento em geladeira até o início do ensaio.

A semeadura das sementes de ciúme (Calotropis procera) foi efetuada em bandejas de isopor, de 128 células, decorrido trinta dias após a semeadura, quando as plantas apresentavam quatro folhas definitivas, finalizou-se $o$ experimento, iniciando-se a mensuração das variáveis. As unidades experimentais, contendo 16 plantas, foram irrigadas diariamente, até a capacidade de campo dos substratos, de modo a manter o vigor das plantas.

Foi contabilizada a percentagem de emergência $(\% \mathrm{E})$, considerando a contagem do número de plântulas emergidas até sua estabilidade durante 15 dias, calculada conforme equação 1, método recomendo por Laboriau e Valadares (1976).

$$
\% E=\frac{N}{A} 100
$$

Em que: \%E - percentagem de emergência das plântulas; $\mathrm{N}$ número de total de plântulas emergidas; $\mathrm{A}$ - número total de sementes colocadas para germinar.

Decorridos 30 dias após o início da germinação procedeu-se da mensuração das variáveis: altura de planta (AP), utilizando-se uma régua graduada em centímetro; número de folhas por planta (NF); diâmetro de caule (DC), com auxílio de um paquímetro digital graduado em 
milímetro; comprimento de raiz (CR); massa seca da parte aérea (MSPA) e massa seca da raiz (MSR) das plantas de ciúme.

A obtenção da massa seca da parte aérea (MSPA) e da massa seca das raízes (MSR) foi por meio da secagem do material em estufa, a uma temperatura constante de $75^{\circ} \mathrm{C}$, por 24 horas, decorrido esse tempo, os valores foram obtidos utilizando-se balança de precisão. A massa seca total (MST) foi calculada pela soma das massas da parte aérea e da raiz.

Determinou-se ainda o índice de qualidade de Dickson (IQD) em função da altura da parte aérea (AP), do diâmetro do coleto (DC), da massa seca da parte aérea (MSPA) e da matéria seca das raízes (MSR), por meio da equação 2 (DICKSON et al., 1960):

$$
I Q D=\frac{M S T(g)}{A P(\mathrm{~cm}) / D C(\mathrm{~mm})+\operatorname{MSPA}(\mathrm{g}) / \operatorname{MSR}(\mathrm{g})}
$$
Em que: IQD - índice de qualidade de Disckson; MST massa seca total; AP - altura de planta; DC - diâmetro de caule; MSPA - massa seca da parte aérea; MSR - massa seca de raiz.

O experimento foi disposto em delineamento inteiramente casualizado, com 12 tratamentos, sendo doze substratos (S1 - areia; S2 - Solo; S3 - Esterco caprino; S4 Bagana; S5 - fibra de coco; S6 - Areia + esterco; S7 - Areia + fibra de coco; S8 - Areia + bagana; S9 - Solo + esterco caprino; S10 - Solo + fibra de coco; S11 - Solo + bagana; S12 - Solo + esterco caprino + bagana) com quatro repetições de 18 sementes cada.

Os dados foram submetidos ao teste de Shapiro-Wilk para verificação da normalidade dos dados, de F para a análise de variância e ao teste de Tukey para a comparação de médias, todos a 5,0\% de probabilidade, utilizando o software ASSISTAT $^{\circledR}$ (SILVA; AZEVEDO, 2016).

\section{RESULTADOS E DISCUSSÃO}

$\mathrm{Na}$ Tabela 1 observam-se os valores médios de percentagem de emergência das plântulas, altura de planta, número de folha por planta, diâmetro de caule, comprimento de raiz, massa seca da parte aérea e massa seca de raiz das plantas de "ciúme" em função de doze substratos.
Observou-se que a \% E nos substratos S1, S2, S4, S6, S11 e S12 não apresentam diferenças estatísticas entre as plântulas emergidas em areia, solo, bagana, solo + bagana e solo + esterco caprino + bagana. A melhor \% $\mathrm{E}$ foi observada no substrato fibra de coco com $100 \%$ (Tabela 1). Um das características em comum nestes substratos são as condições de aeração, deste modo, permite o movimento da água e do ar, assim facilitando a protrusão das sementes de ciúme. Resultados semelhantes para o substrato areia foram encontrados por Oliveira-Bento et al. (2013) sob temperatura média de 25 a $30^{\circ} \mathrm{C}$, deste modo, ratifica sua adaptação em solos arenosos.

Esses resultados são de grande relevância para incrementar os estudos sobre a germinação das sementes de "ciúme", naquelas regiões em que se admite o cultivo desta espécie para sua respectiva utilidade, pois segundo OliveiraBento et al. (2013), a escassez de estudos sobre sementes de Calotropis procera, no que concerne a germinação, limita sua utilização como planta de forma racional, uma vez que não constam informações sobre essa espécie nas Regras para Análise de Sementes.

Para a altura das plantas, não houve diferença significativa entre os substratos S2 e S3 (areia e esterco caprino), a mesma interpretação se aplica para os substratos S6, S9 e S12 (areia + esterco caprino, solo + esterco caprino e solo + esterco caprino + bagana). Uma característica comum nestes substratos é a presença de esterco caprino, por ser de origem orgânica, rico em nutrientes essenciais para o crescimento das plantas, tais como Nitrogênio e Enxofre (ARAÚJO et al., 2010).

$\mathrm{O}$ número de folhas por planta é inerente à altura de planta, neste caso, as plantas com maior número de folhas foi registrado nos substratos S8, S11 e S12 (areia + bagana, solo + bagana e solo + esterco caprino + bagana), sendo estatisticamente iguais, tal comportamento indica que os citados substratos não oferecem variabilidade para esta variável. Assim, se admite afirmar que tais substratos são convenientes para o cultivo desta espécie no semiárido, a qual pode ser utilizada como suporte forrageiro para a alimentação de ovinos, uma vez que suas folhas são ricas em proteínas (TORRES et al., 2010).

Tabela 1. Valores médios das variáveis de porcentagem de emergência (\%E), altura de planta (AP), número de folha por planta (NF), diâmetro de caule (DC), comprimento de raiz (CR), massa seca da parte aérea (MSPA), massa seca de raiz (MSR) e índice de qualidade de Dickson (IQD) das mudas de ciúme (Calotropis procera Aiton) em função de diferentes substratos.

\begin{tabular}{|c|c|c|c|c|c|c|c|c|}
\hline \multirow{2}{*}{ Substratos } & \multicolumn{8}{|c|}{ Variáveis estudadas } \\
\hline & $\% \mathrm{E}$ & $\mathrm{AP}$ & $\mathrm{NF}$ & $\mathrm{DC}$ & $\mathrm{CR}$ & MSPA & MSR & IQD \\
\hline S1 & $78,1 \mathrm{abc}$ & $2,81 \mathrm{~d}$ & $3,8 \mathrm{bc}$ & $1,37 \mathrm{ab}$ & $3,47 \mathrm{ab}$ & $0,120 \mathrm{de}$ & $0,076 \mathrm{a}$ & $0,033 \mathrm{a}$ \\
\hline S2 & $92,1 \mathrm{abc}$ & $3,47 \mathrm{~cd}$ & $3,9 \mathrm{bc}$ & $1,28 \mathrm{abcd}$ & $3,22 \mathrm{abc}$ & $0,183 \mathrm{bcd}$ & $0,054 \mathrm{abc}$ & $0,029 \mathrm{ab}$ \\
\hline S3 & $28,1 \mathrm{~d}$ & $3,65 \mathrm{~cd}$ & $3,0 \mathrm{c}$ & $0,91 \mathrm{~d}$ & $2,09 \mathrm{c}$ & $0,076 \mathrm{e}$ & $0,017 \mathrm{~d}$ & $0,007 \mathrm{e}$ \\
\hline S4 & $92,2 \mathrm{abc}$ & $6,68 \mathrm{ab}$ & $4,3 \mathrm{ab}$ & $0,92 \mathrm{~cd}$ & $2,80 \mathrm{abc}$ & $0,239 \mathrm{abc}$ & $0,026 \mathrm{~cd}$ & $0,014 \mathrm{de}$ \\
\hline S5 & $100,0 \mathrm{a}$ & $7,45 \mathrm{a}$ & $4,0 \mathrm{~b}$ & $1,01 \mathrm{~b} \mathrm{~cd}$ & $3,53 \mathrm{ab}$ & $0,341 \mathrm{a}$ & $0,072 \mathrm{ab}$ & $0,028 \mathrm{ab}$ \\
\hline S6 & $85,9 \mathrm{abc}$ & 4,76a bcd & $3,9 \mathrm{bc}$ & $1,31 \mathrm{abc}$ & $3,36 \mathrm{ab}$ & $0,213 \mathrm{bcd}$ & $0,051 \mathrm{abcd}$ & $0,027 \mathrm{abc}$ \\
\hline S7 & $70,3 \mathrm{c}$ & $4,70 \mathrm{bcd}$ & $3,7 \mathrm{bc}$ & $1,41 \mathrm{a}$ & $3,20 \mathrm{abc}$ & 0,180 bcde & $0,042 \mathrm{bcd}$ & $0,023 \mathrm{abcd}$ \\
\hline S8 & $75,0 \mathrm{bc}$ & $2,89 \mathrm{~d}$ & $5,2 \mathrm{a}$ & 1,29 abcd & $3,97 \mathrm{a}$ & 0,139 cde & $0,022 \mathrm{~cd}$ & 0,015 cde \\
\hline S9 & $40,6 \mathrm{~d}$ & $5,22 \mathrm{abcd}$ & $3,0 \mathrm{c}$ & $1,11 \mathrm{abcd}$ & $2,64 \mathrm{bc}$ & 0,165 cde & $0,041 \mathrm{bcd}$ & $0,018 \mathrm{~b}$ cde \\
\hline S10 & $96,8 \mathrm{ab}$ & $6,01 \mathrm{abc}$ & $3,9 \mathrm{bc}$ & 1,27 abcd & $3,91 \mathrm{a}$ & $0,276 \mathrm{ab}$ & $0,078 \mathrm{a}$ & $0,033 \mathrm{a}$ \\
\hline S11 & $78,1 \mathrm{abc}$ & $4,45 \mathrm{bcd}$ & $4,9 \mathrm{a}$ & 1,07 abcd & $3,80 \mathrm{ab}$ & $0,331 \mathrm{a}$ & $0,061 \mathrm{ab}$ & $0,034 \mathrm{a}$ \\
\hline S12 & $81,3 \mathrm{abc}$ & $5,41 \mathrm{abcd}$ & $4,9 \mathrm{a}$ & $0,91 \mathrm{~d}$ & $3,43 \mathrm{ab}$ & $0,236 a b c$ & $0,044 \mathrm{abcd}$ & $0,021 \mathrm{bcd}$ \\
\hline $\mathrm{CV}(\%)$ & 20,2 & 23,7 & 3,1 & 28,7 & 23,7 & 22,1 & 27,6 & 26,9 \\
\hline
\end{tabular}

(S1 - areia; S2 - Solo; S3 - Esterco caprino; S4 - Bagana; S5 - fibra de coco; S6 - Areia + esterco; S7 - Areia + fibra de coco; S8 - Areia + bagana; S9 - Solo + esterco caprino; S10 - Solo + fibra de coco; S11 - Solo + bagana; S12 - Solo + esterco caprino + bagana). Os valores seguidos pela mesma letra não diferem estatisticamente entre si pelo teste de Tukey a 5\% de probabilidade. CV: Coeficiente de variação. 
O diâmetro caulinar é de grande importância para qualquer vegetal, sendo à base de sustentação das plantas que auxilia em seu vigor (MENEZES et al., 2013). De acordo com a análise estatística, as plantas que apresentaram o mesmo diâmetro de caule foram nos substratos: S2, S8, S9, S10 e S11 (solo, areia + bagana, solo + esterco caprino, solo + fibra de coco e solo + bagana).

$\mathrm{O}$ crescimento radicular $(\mathrm{CR})$ foi maior nos substratos S8 e S10 (areia + bagana e solo + fibra de coco), possivelmente, tal fato está relacionado com as condições granulométricas destes substratos, que pode ter viabilizado boas condições de aeração, assim, a água contida nos poros de maior diâmetro drenam facilmente, este fenômeno poderá estimular crescimento radicular em busca de água (solução do solo), o menor CR foi observado no esterco caprino (S3).

De acordo com Carneiro (1983) o substrato exerce influência marcante na arquitetura do sistema radicular e no estado nutricional das plantas, afetando profundamente a qualidade das mudas. Segundo Zietemann e Roberto (2007), o substrato destina-se a sustentar as plantas durante o enraizamento e servir de fonte de nutrientes para as plantas, além de fornecer aeração adequada, e capacidade de retenção de líquido satisfatória para oferecer umidade adequada às mudas.

A biomassa seca da parte aérea (MSPA) das plantas de "ciúme" foi igual estaticamente nos substratos S2, S6 e S7 (solo, areia + esterco caprino e areia + fibra de coco), a maior MSPA das plantas foi observada nos substratos S5 e S10 (fibra de coco e solo + fibra de coco), respectivamente, fato relacionado com a alta percentagem de emergência das plântulas e a altura de planta, ou seja, substratos combinado com fibra de coco proporcionaram melhor desenvolvimento da parte aérea das plantas nele cultivadas, deste modo, ratifica que a $C$. procera é uma espécie que possui potencial forrageiro para alimentação dos rebanhos, no Nordeste brasileiro.

Araújo et al. (2015) observaram que a massa seca da raiz de plântulas comportou-se de forma semelhante, tendo em vista que a adubação com esterco influenciou de forma negativa, sendo o tratamento sem esterco superior aos demais tratamentos que faziam uso em diferentes concentrações. Atribuíram esses resultados como uma estratégia da planta em investir suas reservas em fitomassa radicular em busca de nutrientes, em virtude do tratamento constituído apenas pelo solo apresentar um menor aporte de nutrientes em relação aos demais. O incremento positivo para a maioria das variáveis em função da utilização do esterco demonstra que sua utilização promove um efeito benéfico no desenvolvimento de plântulas de Sterculia foetida, destinando suas reservas principalmente no crescimento da parte aérea das plântulas.

A biomassa radicular está relacionada à emergência das plântulas, como se observa nos resultados para grande parte dos substratos (Tabela 1).

No que diz respeito à qualidade de mudas de Calotropis procera com base no crescimento, medida pelo índice de qualidade de Dickson (IQD), pode-se observar na Tabela 1 que os valores de IQD não diferiram entre os substratos S1 (areia), S2 (solo normal), S5 (fibra de coco), S6 (areia + esterco caprino), S7 (areia + fibra de coco), S9 (solo + esterco caprino), S10 (solo + fibra de coco) e S11 (solo + bagana), ou seja, para tais substratos e suas combinações, apresentam mudas de qualidade semelhante.
Observou-se ainda que os maiores valores de IQD são ressaltados nos substratos: areia, solo + fibra de coco e solo + bagana, tal comportamento certamente se deve as condições de maior aeração em decorrência da natureza do material, deste modo, influencia diretamente na morfologia das mudas. No esterco caprino quanto à qualidade das mudas apresentou resultado menos expressivo segundo o valor de IQD, diferindo de todos os outros substratos, isso indica que o esterco caprino puro não pode ser utilizado para a produção de mudas, possivelmente por conter elementos no seu material que inibem a qualidade das mudas de ciúme.

\section{CONCLUSÕES}

Os substratos quando combinados com fibra de coco, bagana e esterco caprino proporcionam melhores condições de vigor e melhor desenvolvimento da parte aérea das plantas de ciúme. Os substratos não ideais para emergência de plântulas de Calotropis procera são esterco caprino (S3) e solo + esterco caprino (S9).

\section{REFERÊNCIAS}

ALEXANDRE, R. S.; WAGNER JUNIOR, A.; NEGREIROS, J. R. S.; BRUCKNER, C. H. Estádio de maturação dos frutos e substratos na germinação de sementes e desenvolvimento inicial de plântulas de jabuticabeira. Revista Brasileira de Agro ciência, v.12, n.2, p.227-230, 2006.

ARAÚJO, L. H. B.; CHAGAS, K. P. T.; NÓBREGA, C. C.; ARAÚJO, F. S.; VIEIRA, F. A. Efeito do esterco na emergência e crescimento inicial de plântulas de Sterculia foetida L. Nativa: pesquisas agrárias e ambientais, v. 03, n. 01, p. 22-26, 2015. DOI: http://dx.doi.org/10.14583/23187670.v03n01a04

ARAÚJO, W. B. M.; ALENCAR, R. D.; MENDONÇA, V.; MEDEIROS, E. V.; ANDRADE, R. C.; ARAÚJO, R. R. Esterco caprino na composição de substratos para formação de mudas de mamoeiro. Ciência e Agrotecnologia, v. 34, n. 1, p. $68-73,2010$.

BARROS, F. E. V.; SOUSA, M. G. T.; COSTA, J. L.; OLEA, R. S. G.; FREIRE, S. M. F.; BORGES, A. C. R.; BORGES, M. O. R. Avaliação das atividades analgésica e antinflamatória do extrato metanólico de Calotropis procera, R. Br. (ciúme). Revista Infarma - Ciências Farmacêuticas, v. $16, n^{\circ} .9 / 10$, p. $60-64,2004$.

BRASIL. Ministério da Agricultura, Pecuária e Abastecimento. Regras para análise de sementes. Secretaria de Defesa Agropecuária. Brasília, DF: MAPA/ACS, 365p. 2009.

BRASIL. Ministério da Agricultura. Plano Estadual dos Recursos Hídricos do Ceará: dados climatológicos de Sobral - CE (1961 - 1988). Brasília, 1990.

CARNEIRO, J. G. A. Variações na metodologia de produção de porta-enxerto florestais afetam os parâmetros morfofisiológicos que indicam a sua qualidade. FUPEF: Curitiba, n.12, p.1-40. 1983. 
DIAS, M. A.; LOPES, J. C.; CORRÊA, N. B.; DIAS, D. C. F. S. Germinação de sementes e desenvolvimento de plantas de pimenta malagueta em função do substrato e da lâmina de água. Revista Brasileira de Sementes, v. 30, n. 3, p. 115-121, 2008 .

DICKSON, A.; LEAF, A. L.; HOSNER, J. F. Quality appraisal of white spruce and white pine seedling stock in nurseries. The Forestry Chronicle, v. 36, p. 10-13,1960.

FABRICANTE, J. R.; OLIVEIRA, M. N. A.; SIQUEIRAFILHO, J. A. Aspecto da ecologia de Colatropis procera (Apocynaceae) em uma área de Caatinga alterada pelas obras do projeto de Integração do Rio São Francisco em Mauriti, CE. Rodriguésia-Instituto de Pesquisa Jardim Botânico do Rio de Janeiro, v. 64, n. 3, p. 647-654, 2013.

GALLEGOS-OLEA, R. S.; BORGES, M. O. R.; BORGES, A. C. R.; FREIRE, S. M. F.; SILVEIRA, L. M. S.; VILEGAS, W. Flavonoides de Calotropis procera R. Br. (Asclepiadeceae). Revista Brasileira de Plantas Medicinais, v. 18, n. 4, p. 627-648, 2008.

GARCEZ, B. S.; CÂMARA, C. S.; VASCONCELOS, V. R. Utilização da flor de seda (Calotropis procera) e do matapasto (Senna obtusifolia) na alimentação de ruminantes Revista eletrônica Nutritime, v. 11, n. 3, p.3500-3507, 2014

GOMES, J. M.; COUTO, L.; LEITE, H. G.; XAVIER, A.; GARCIA, S. L. R. Parâmetros morfológicos na avaliação da qualidade de mudas de Eucalyptus grandis. Revista Árvore, v. 26, n. 6, p.655-664, 2002.

JOLY, A. B. Botânica. Introdução à taxonomia vegetal. 5. ed. São Paulo: Nacional, 777p. 1979.

LABORIAU, L. G., VALADARES, M. B. On the germination of seeds of Calotropis procera. Anais da Academia Brasileira de Ciências, v, 48, p. 174-186, 1976.

LINDLEY, J. Flora Médica. Ajay Book Services, New Delli. 375p. 1985.

MELlO, M. M.; VAZ, A. A.; GONÇALVES, L. C.; SATURNINO, H. M. Estudo fitoquímico da Calotropis procera Ait., sua utilização na alimentação de caprinos: efeitos clínicos e bioquímicos séricos. Revista Brasileira Saúde Produção Animal, v. 2, p. 15-20, 2001.
MENEZES, A. S.; MOREIRA, F. J. C.; SOUZA, M. C. M. R.; SILVA, M. C. B. Efeito do substrato no processo de germinação em duas variedades de mamão. Revista Agrogeoambiental, v. 5, n. 3, 2013. DOI: http://dx.doi.org/10.18406/2316-1817v5n32013516

OLIVEIRA-BENTO, S. R. S.; TORRES, S. B.; OLIVEIRA, F. N.; PAIVA, E. P.; BENTO, D. A. V. Biometria de frutos e sementes e germinação de Calotropis procera Aiton (Apocynaceae). Revista Bioscience Journal, v. 29, n. 5, p. 1194-1205, 2013.

OLIVEIRA, V. M.; SOUTO, J. S. Estimativa da produção de biomassa de Calotropis procera (Ait) R. Br., e avaliação de sua composição química no Estado da Paraíba. Revista Verde, v. 4, n. 1, p. 161-161, 2009

SILVA, C. G.; MARINHO, M. G. V.; LUCENA, M. F. A.; COSTA, J. G. M. Levantamento etnobotânico de plantas medicinais em área de Caatinga na comunidade do Sítio Nazaré, município de Milagres, Ceará, Brasil. Revista Brasileira de Plantas Medicinais, v.17, n.1, p.133-142, 2015.

SILVA, F. A. S.; AZEVEDO, C. A. V. The Assistat Software Version 7.7 and its use in the analysis of experimental data. African Journal of Agricultural Research, v.11, n.39, p.37333740, 2016. https://doi. org/10.5897/AJAR2016.11522.

TANIRA, M. O. M. Antimicrobial and phytochemical screening of medicinal plants of the United Arab Emirates. Journal of Ethnopharmacology, v. 41, p. 201-205, 1994.

TORRES, J. F.; BRAGA, A. P.; LIMA, G. F. C.; RANGEL, A. H. N.; LIMA JÚNIOR, D. M.; MACIEL, M. V.; OLIVEIRA, S. E. O. Utilização do feno de flor-de-seda (Calotropis procera Ait. R. Br) na alimentação de ovinos. Acta Veterinária Brasílica, v. 4, n. 1, p. 42-50, 2010.

WAGNER JUNIOR, A.; ALEXANDRE, R. S.; NEGREIROS, J. R. S.; PIMENTEL, L. D.; SILVA, J. O. C.; BRUCKNER, C. H. Influência do substrato na germinação e desenvolvimento inicial de plantas de maracujazeiro amarelo (Passiflora edulis Sims f. flavicarpa Deg). Ciência e Agrotecnologia, v. 30, n. 4, p. 643-647, 2006.

ZIETEMANN, C.; ROBERTO, S. R. Produção de mudas de goiabeira (Psidium guajava L.) em diferentes substratos. Revista Brasileira de Fruticultura, v. 29, n.1, p.137-142, 2007. 